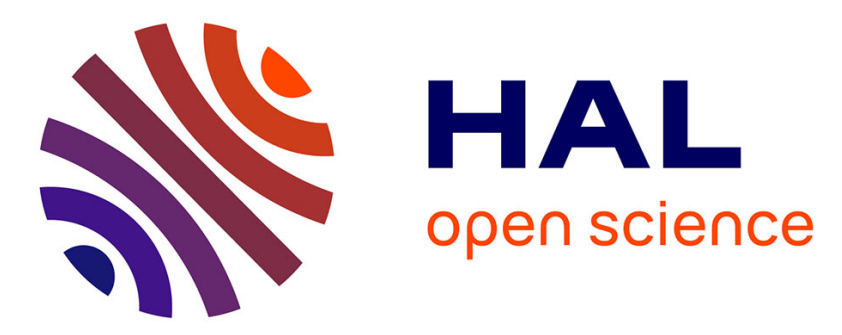

\title{
Induction motor control in presence of magnetic saturation: Speed regulation and power factor correction
}

Abderrahim Elfadili, Fouad Giri, Abdelmounime El Magri, Luc Dugard, Hamid Ouadi

\section{- To cite this version:}

Abderrahim Elfadili, Fouad Giri, Abdelmounime El Magri, Luc Dugard, Hamid Ouadi. Induction motor control in presence of magnetic saturation: Speed regulation and power factor correction. ACC 2011 - American Control Conference, Jun 2011, San Francisco, United States. pp.5406-5411. hal00681563

\section{HAL Id: hal-00681563 https://hal.science/hal-00681563}

Submitted on 21 Mar 2012

HAL is a multi-disciplinary open access archive for the deposit and dissemination of scientific research documents, whether they are published or not. The documents may come from teaching and research institutions in France or abroad, or from public or private research centers.
L'archive ouverte pluridisciplinaire HAL, est destinée au dépôt et à la diffusion de documents scientifiques de niveau recherche, publiés ou non, émanant des établissements d'enseignement et de recherche français ou étrangers, des laboratoires publics ou privés. 


\title{
Induction Motor Control in Presence of Magnetic Saturation: Speed Regulation and Power Factor Correction
}

\author{
A. El Fadili, F. Giri, A. El Magri, L. Dugard, H. Ouadi.
}

\begin{abstract}
Controlling induction motors have been given a great deal of interest. Generally, the control issue has been dealt with, neglecting the saturation effect of the magnetic characteristic and ignoring the presence of the $\mathrm{AC} / \mathrm{DC} / \mathrm{AC}$ converter. The originality of the present work is twofold: (i) the magnetic saturation effect is accounted for in the control design model; (ii) the induction motor is considered together with its $\mathrm{AC} / \mathrm{DC} / \mathrm{AC}$ converter. The control objectives for the association 'converter-machine' are: (i) forcing the motor speed to track a varying reference signal and optimizing the rotor flux reference, (ii) regulating the DC Link voltage, (iii) assuring a satisfactory power factor correction (PFC) with respect to the power supply net. A nonlinear multi-loop controller is designed using the backstepping technique and formally analyzed using Lyapunov stability and averaging theory. In addition to closed-loop stability, it is proved that all control objectives (motor speed tracking, DC link voltage regulation and unitary power factor) are asymptotically achieved, up to unavoidable, but small, harmonic errors (ripples).
\end{abstract}

\section{INTRODUCTION}

$\mathrm{W}$ HEN three-phase induction motors are involved, speed variation is performed through (three-phase) DC/AC inverters due to their high capability of performing flexible voltage and frequency variation. The inverters are generally powered by an AC supply net through (a transformer and) an AC/DC rectifier. The connection line between the rectifier and the inverter is called DC link. The control problem at hand is to design a controller ensuring a wide speed range regulation for the system including the $\mathrm{AC} / \mathrm{DC}$ rectifier, the $\mathrm{DC} / \mathrm{AC}$ inverter and the induction motor. The point is that such a system behaves (vis-à-vis to the AC supply grid) as a nonlinear load causing generation of undesirable current harmonics that reduce the rectifier efficiency, induce voltage distortion in the AC supply line and cause electromagnetic compatibility issues. To overcome this drawback, the control objective must consider not only the motor speed regulation but also the current harmonics rejection. The last feature is referred to as the power factor correction (PFC) [8]

Previous works on induction machine speed control simplified the control problem by: (i) ignoring the dynamics of the $\mathrm{AC} / \mathrm{DC}$ rectifier (focusing thus only on the set 'DC/AC inverter - Motor'); (ii) neglecting the saturation

Manuscript received September 2, 2010.

F. Giri is with GREYC Lab, UMR CNRS, University of Caen, France.

A. El Fadili, A. El Magri H. Ouadi are with EMI, LAII, Rabat, Marocco.

L. Dugard is with GIPSA Lab, UMR CNRS, Grenoble-INP, France.

Corresponding author: A. El Fadili, elfadili_abderrahim@yahoo.fr effects in the motor magnetic circuit. The simplified control problem has been dealt with, using several control strategies ranging from simple techniques, e.g. field-oriented control [3], to more sophisticated nonlinear approaches, e.g. direct torque control [6]. Neglecting the AC/DC rectifier was coped with, supposing the DC link voltage to be perfectly regulated and considering the $\mathrm{PFC}$ requirement not to be an issue. Of course, this assumption is not necessarily satisfied. On the other hand, neglecting the magnetic saturation effects makes it impossible to consider state-dependent flux references. Specifically, the reference flux (in previous control solutions) is taken constant equal to its nominal value, [3], [6]. Obviously, the machine efficiency is then maximal only when it operates in the neighborhood of its nominal point. If the operation point is below the nominal value (small loads), the useless energy stored in stator inductances reduces the machine efficiency. On the other hand, if the operation point is above the nominal value, the (overloaded) machine operates in the saturation zone of its magnetic characteristic and the control performances are not ensured because the control model based upon is no longer representative of the machine. To overcome the above shortcomings in speed control, the flux reference must be dependent on both the speed reference and torque-load. But this requirement is only achievable if the nonlinear nature of the magnetic characteristic is accounted for in the model.

In the present work, a new control strategy is developed for the whole system including the 'AC/DC rectifier' and the association 'DC/AC inverter-induction motor'. The new strategy involves a nonlinear multi-loop controller obtained using a model that accounts for the saturation effect of the motor magnetic circuit [7]. It is designed using the Lyapunov and backstepping design techniques, bearing in mind three main control objectives, namely motor speed tracking of varying reference trajectories, rotor flux optimization and unitary power factor. Flux optimality consists in minimizing the absorbed stator current that is necessary to produce a given motor torque. It is formally proved that all control objectives are achieved with a good accuracy.

\section{MODELING THE 'AC/DC/AC CONVERTER-INDUCTION MOTOR' ASSOCIATION}

The controlled system, illustrated by Fig 1, includes an $\mathrm{AC} / \mathrm{DC}$ boost rectifier and a combination 'inverter-induction motor'. The inverter is a DC/AC converter operating, like the AC/DC rectifier, according to the known Pulse Wide Modulation (PWM) principle. 


\section{A. AC/DC rectifier modeling}

The power supply net is connected to an H-bridge converter which consists of four IGBT's with anti-parallel diodes for bidirectional power flow mode. This is expected to accomplish two main tasks: (i) providing a constant DC link voltage; (ii) providing an almost unitary power factor. Recall here the average model of (AC / DC) rectifier developed in [9]:

$\dot{x}_{1}=\left(v_{e}-u_{1} x_{2}\right) / L_{1}, \dot{x}_{2}=\left(u_{1} x_{1}-\bar{i}_{s}\right) / 2 C$

where:

$x_{1}=\bar{i}_{e}, x_{2}=\bar{v}_{d c}, u_{1}=\bar{s}$

are respectively the average values of $i_{e}, v_{d c}$ and $s$, over cutting periods. The switch position $s$ is a function taking values in the discrete set $\{-1,1\}$. Specifically:

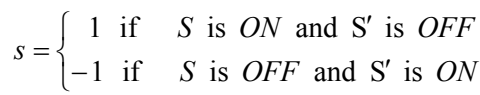

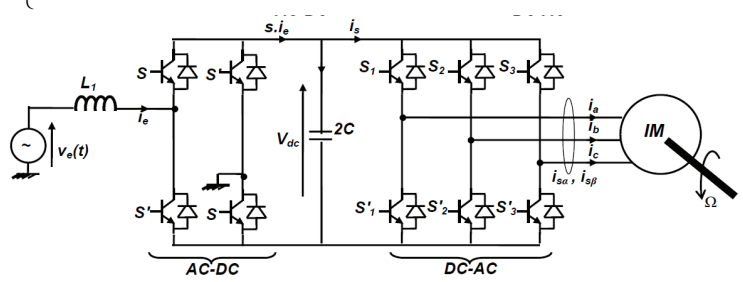

Fig.1. AC/DC/AC drive circuit with a three-level inverter

\section{$B$. Inverter-Motor modeling}

In [7], a new model was developed and experimentally validated for the considered induction motor. Its originality lies in the fact that it takes into account the saturation effect of the machine magnetic characteristics (fig 2). It is defined by the following state space representation:

$J \dot{\Omega}=-f \Omega+p\left(\phi_{r \alpha} i_{s \beta}-\phi_{r \beta} i_{s \alpha}\right)-T_{L}$

$\dot{i}_{s \alpha}=-a_{2} i_{s \alpha}+\delta \phi_{r \alpha}+a_{3} p \Omega \phi_{r \beta}+a_{3} v_{s \alpha}$

$\dot{i}_{s \beta}=-a_{2} i_{s \beta}-a_{3} p \Omega \phi_{r \alpha}+\delta \phi_{r \beta}+a_{3} v_{s \beta}$

$\dot{\phi}_{r \alpha}=a_{1} i_{s \alpha}-L_{s e q} \delta \phi_{r \alpha}-p \Omega \phi_{r \beta}$

$\dot{\phi}_{r \beta}=a_{1} i_{s \beta}-L_{s e q} \delta \phi_{r \beta}+p \Omega \phi_{r \alpha}$

$\delta$ is a varying parameter that depends on the machine magnetic state (see Fig 2). In [7], this dependence was given a polynomial approximation, i.e.:

$\delta=\Gamma\left(\Phi_{r}\right)=q_{0}+q_{1} \Phi_{r}+\ldots+q_{m} \Phi_{r}^{m}$

The involved coefficients have been experimentally identified in [7] using Fig 3. $\Phi_{r}$ denotes the amplitude of the (instantaneous) rotor flux, denoted $\phi_{r}$. Consequently:

$\Phi_{r}=\sqrt{\phi_{r \alpha}^{2}+\phi_{r \beta}^{2}}$

where $\phi_{r \alpha}, \phi_{r \beta}$ denote the rotor flux $\alpha \beta$-components. $\left(i_{s \alpha}, i_{s \beta}\right)$ are the $\alpha \beta$-components of the stator current, $\Omega$ represents the motor speed, $R_{s}, R_{r}$ denote the stator and rotor resistances, $T_{L}$ represents the load torque, $J$ is the combined rotor and load inertia, $p$ is the number of pole pairs, $L_{s e q}$ is the equivalent inductance (of both stator and rotor leakages) as this is seen from the stator,

$a_{1}=R_{r}, a_{3}=\left(L_{s e q}\right)^{-1}, a_{2}=a_{3}\left(R_{s}+R_{r}\right)$

The numerical values of the model parameters are those of [7] where the model is experimentally validated using an induction motor of $7.5 \mathrm{KW}$ power.

In (3a-e), $v_{s \alpha}, v_{s \beta}$ denote the stator voltage components in $\alpha \beta$-coordinates (Park's transformation of the three-phase stator voltages). The inverter is featured by the fact that the stator $\alpha$ - and $\beta$-voltages can be controlled independently. To this end, these voltages are expressed in function of the corresponding control action

$v_{s \beta}=v_{d c} u_{3}, v_{s \alpha}=v_{d c} u_{2}$

where $\left(u_{2}, u_{3}\right)$ represent the average $\alpha$ - and $\beta$-axes of the three-phase duty ratio system $\left(s_{1}, s_{2}, s_{3}\right)$. The latter are obtained from (1c) replacing there $\left(S, S^{\prime}\right)$ by $\left(S_{i}, S_{i}^{\prime}\right)$ $(i=1,2,3)$. Now, let us introduce the state variables:

$x_{3}=\bar{\Omega}, \quad x_{4}=\bar{i}_{s \alpha}, \quad x_{5}=\bar{i}_{s \beta}, x_{6}=\bar{\phi}_{r \alpha}, x_{7}=\bar{\phi}_{r \beta}$

Using the power conservation principle, one gets:

$\bar{i}_{s}=\left(u_{2} x_{4}+u_{3} x_{5}\right)$

Substituting (4a-c) and (5) in (3a-f), the state space equations obtained up to now are put together to get a state space model of the whole system including the AC/DC/AC converters combined with the induction motor. For convenience, the whole averaged model is rewritten here for future reference:

$$
\begin{aligned}
& \dot{x}_{1}=\left(v_{e}-u_{1} x_{2}\right) / L_{1} \\
& \dot{x}_{2}=\left(u_{1} x_{1}-\bar{i}_{s}\right) / 2 C \\
& J \dot{x}_{3}=-f x_{3}+p\left(x_{6} x_{5}-x_{7} x_{4}\right)-T_{L} \\
& \dot{x}_{4}=-a_{2} x_{4}+\delta x_{6}+a_{3} p x_{3} x_{7}+a_{3} u_{2} x_{2} \\
& \dot{x}_{5}=-a_{2} x_{5}-a_{3} p x_{3} x_{6}+\bar{\delta} x_{7}+a_{3} u_{3} x_{2} \\
& \dot{x}_{6}=a_{1} x_{4}-L_{s e q} \bar{\delta} x_{6}-p x_{3} x_{7} \\
& \dot{x}_{7}=a_{1} x_{5}-L_{s e q} \bar{\delta} x_{7}+p x_{3} x_{6} \\
& \left.\bar{\Phi}_{r}=\sqrt{\left(x_{6}{ }^{2}+x_{7}{ }^{2}\right.}\right) \\
& \bar{\delta}=\Gamma\left(\bar{\Phi}_{r}\right)=q_{0}+q_{1} \bar{\Phi}_{r}+\ldots+q_{m} \bar{\Phi}_{r}^{m}
\end{aligned}
$$

\section{CONTROLLER DESIGN}

\section{A. Control objectives}

Two operational control objectives are looked for:

(i) Speed regulation with optimization of the rotor flux norm reference: the machine speed $\Omega$ must track a varying reference $\Omega_{\text {ref }}$ as closely as possible while the rotor flux norm reference must be online adjusted so that the stator current consumption is minimized by acting on.

(ii) PFC requirement: the rectifier input current $i_{e}$ must be sinusoidal and in phase with the AC supply voltage $v_{e}$. 
As three control inputs are at hand (namely $u_{1}, u_{2}$ and $u_{3}$ ) two additional control objectives will be pursued:

(iii) Controlling the continuous voltage $v_{d c}$, making it track a given reference signal $v_{d c r e f}$. This reference is generally set to a constant value equal to the nominal voltage entering the inverter.

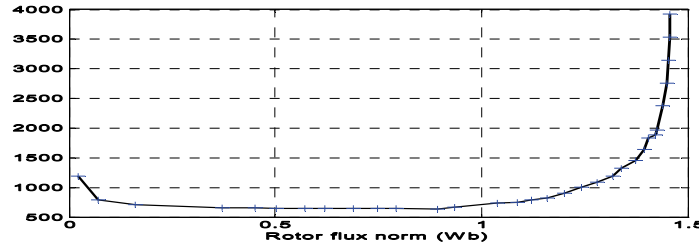

Fig.2. Characteristic $\left(\delta, \Phi_{r}\right)$ : directly computed points $(++)$ and polynomial interpolation (solid). Unities: $\delta\left(\Omega H^{-2}\right), \Phi_{r}(\mathrm{~Wb})$

\section{B. AC/DC rectifier control design}

1) Controlling rectifier input current to meet $P F C$

The PFC objective means that the average input current rectifier must be sinusoidal and in phase with the AC supply voltage. This amounts to enforce the current $x_{1}$ to track a reference signal $x_{1}^{*}$ of the form:

$x_{1}^{*}=k v_{e}$

At this point $k$ is any real parameter that is allowed to be time-varying. Introduce the current tracking error:

$z_{1}=x_{1}-x_{1}^{*}$

In view of (6a), the above error undergoes the following equation:

$\dot{z}_{1}=\left(v_{e}-u_{1} x_{2}\right) / L_{1}-\dot{x}_{1}^{*}$

To get a stabilizing control law for this first-order system, consider the quadratic Lyapunov function $V_{1}=0.5 z_{1}^{2}$. It can be easily checked that the time-derivative $\dot{V}_{1}$ is a negative definite function of $z_{1}$ if the control input is chosen to be:

$u_{1}=L_{1}\left(c_{1} z_{1}+\left(v_{e} / L_{1}\right)-\dot{x}_{1}^{*}\right) / x_{2}$

where $c_{1}>0$ is a design parameter. The properties of such a control law are summarized in the following proposition.

Proposition 1. Consider the system, next called current (or inner) loop, composed of the current equation (6a) and the control law (10) where $c_{1}>0$ is arbitrarily chosen by the user. If the reference $x_{1}^{*}=k v_{e}$ and its first time derivative are available, then one has the following properties:

a) The current loop satisfies the equation $\dot{z}_{1}=-c_{1} z_{1}$ which is globally exponentially stable i.e. $z_{1}$ exponentially vanishes, whatever the initial conditions.

b) If in addition $k$ converges (to a finite value), then the PFC requirement is asymptotically fulfilled i.e. the (average) input current $x_{1}$ tends (exponentially fast) to its reference $k v_{e}$ as $t \rightarrow \infty \quad$

2) DC link voltage regulation

The aim is now to design a tuning law for the ratio $k$ in (7) so that the rectifier output voltage $x_{2}=\bar{v}_{d c}$ is steered to a given reference value $v_{d c r e f}$. As mentioned above, $v_{d c r e f}$ is generally (but not mandatory) chosen to be the constant nominal inverter input voltage amplitude (i.e. the nominal stator voltage).

\section{a) Relationship between $k$ and $x_{2}$}

The first step in designing such a loop is to establish the relation between the ratio $k$ (control input) and the output voltage $x_{2}$. This is the subject of the following proposition.

Proposition 2. Consider the power rectifier described by (6a-b) together with the control law (10). Under the same assumptions as in Proposition 1, one has the following properties:

1) The output voltage $x_{2}$ varies, in response to the tuning ratio $k$, according to the equation:

$\dot{x}_{2}=\left(k v_{e}^{2}+z_{1} v_{e}\right) / 2 C x_{2}-\left(u_{2} x_{4}+u_{3} x_{5}\right) / 2 C$

2) The squared voltage $\left(y=x_{2}^{2}\right)$ varies, in response to the tuning ratio $k$, according to the equation:

$\dot{y}=k v_{e}^{2} / C+z_{1} v_{e} / C+\chi(x, t)$

with

$\chi(x, t)=-x_{2}\left(u_{2} x_{4}+u_{3} x_{5}\right) / C$

b) Squared DC-link voltage regulation.

The ratio $k$ appears as a control signal in the system defined by (12). As said before, the reference signal $y_{\text {ref }} \stackrel{d e f}{=} v_{d c r e f}^{2}$ (of the squared DC-link voltage $x_{2}=\bar{v}_{d c}$ ) is chosen to be constant and is given the nominal inverter input voltage value. Then, it follows from (12) that the tracking error $z_{2}=y-y_{\text {ref }}$ undergoes the following equation:

$$
\begin{aligned}
\dot{z}_{2}= & E^{2} k / C+E^{2} k \cos \left(2 \omega_{e} t\right) / C \\
& +\sqrt{2} E z_{1} \cos \left(\omega_{e} t\right) / C+\chi(x, t)-\dot{y}_{r e f}
\end{aligned}
$$

where we have used the fact that $v_{e}=\sqrt{2} \cdot E \cdot \cos \left(\omega_{e} t\right)$ and $v_{e}^{2}=E^{2}\left(1+\cos \left(2 \omega_{e} t\right)\right)$. To get a stabilizing control law for the system (15), consider the following Lyapunov function: $V_{2}=0.5 z_{2}^{2}$

It is easily checked that the time-derivative $\dot{V}_{2}$ can be made negative definite in the state $z_{2}$ by letting:

$$
\begin{aligned}
& k E^{2}+k E^{2} \cos \left(2 \omega_{e} t\right)+ \sqrt{2} E z_{1} \cos \left(\omega_{e} t\right)= \\
& C\left(-c_{2} z_{2}-\chi(x, t)\right)+C \dot{y}_{r e f}
\end{aligned}
$$

where $c_{2}>0$ is a design parameter. Bearing in mind the fact that the first derivative of the control ratio $k$ must be available (Proposition 1), one suggests, as a tuning law for such a ratio, the following filtered version of the above solution:

$\dot{k}+d k=d C\left(-c_{2} z_{2}-\chi(x, t)\right) / E^{2}+d C \dot{y}_{r e f} / E^{2}$ 
At this point, the regulator parameters $\left(d, c_{2}\right)$ are any positive real constants. The way these parameters should be chosen will be made clear later (see Theorem 1). For now, let us describe the two control loops we have designed.

Proposition 3. Consider the control system consisting of the $A C / D C$ rectifier described by (6a-b) together with the control laws (10) and (18). Using Proposition 1 (Part 1), it follows that the resulting closed-loop undergoes, in the $\left(z_{1}, z_{2}, k\right)$-coordinates, the following equation where $z_{2}=y-y_{r e f}, b_{0}=E^{2} / C$; and $b_{1}=d C / E$ :

$$
\begin{aligned}
& \left(\begin{array}{c}
\dot{z}_{1} \\
\dot{z}_{2} \\
\dot{k}
\end{array}\right)=\left(\begin{array}{ccc}
-c_{1} & 0 & 0 \\
0 & 0 & b_{0} \\
0 & -b_{1} c_{2} & -d
\end{array}\right)\left(\begin{array}{c}
z_{1} \\
z_{2} \\
k
\end{array}\right)+\left(\begin{array}{c}
0 \\
1 \\
-b_{1}
\end{array}\right) \chi(x, t) \\
& +\left(\begin{array}{c}
E^{2} k \cos \left(2 \omega_{e} t\right) / C+\sqrt{2} E z_{1} \cos \left(\omega_{e} t\right) / C \\
0
\end{array}\right)-\left(\begin{array}{c}
0 \\
1 \\
-b_{1}
\end{array}\right) \dot{y}_{r e f}
\end{aligned}
$$

\section{Motor speed and rotor flux norm regulation}

\section{a) Optimal flux reference generation}

A key feature of the model (6a-j) is that it accounts for the the saturation feature of the motor magnetic characteristic. This feature makes possible the generation of optimal flux references. Presently, optimality is intended in the sense of minimizing the stator current necessary to produce a given load torque. In [1], it was shown that the optimal flux reference $\Phi_{r e f}$ is a function of the stator current. This function was also given a polynomial representation of the form:

$$
\begin{aligned}
& \Phi_{r e f}=\xi\left(\bar{I}_{s}\right)=h_{0}+h_{1} \bar{I}_{s}+h_{2} \bar{I}_{s}^{2}+\ldots+h_{n} \bar{I}_{s}^{n} \\
& \quad \text { with } \\
& \bar{I}_{s}{ }^{2}=x_{4}{ }^{2}+x_{5}{ }^{2}
\end{aligned}
$$

\section{b) Speed and flux controller design and analysis}

A regulator will now be designed to make the rotor speed and flux norm follow their references $\Omega_{\text {ref }}$ and $\Phi_{\text {ref }}=\xi\left(\bar{I}_{s}\right)$. The signal $\Omega_{\text {ref }}$ is any bounded and derivable function of time and its two first derivatives are available and bounded. These properties can always be achieved by filtering the reference through a second-order linear filter. The regulator design is performed in two steps using the backstepping technique [5]. First, introduce the tracking errors:

$z_{3}=\Omega_{\text {ref }}-x_{3}$

$z_{4}=\Phi_{\text {ref }}^{2}-\left(x_{6}{ }^{2}+x_{7}{ }^{2}\right)$

Step 1. It follows from (6c) and (6f-g) that the errors $z_{3}$ and $z_{4}$ undergo the following differential equations:

$\dot{z}_{3}=\dot{\Omega}_{r e f}-p\left(x_{6} x_{5}-x_{7} x_{4}\right) / J+T_{L / J}+f x_{3} / J$

$\dot{z}_{4}=2 \Phi_{\text {ref }} \dot{\Phi}_{\text {ref }}-2 a_{1}\left(x_{6} x_{4}+x_{7} x_{5}\right)+2 L_{s e q} \bar{\delta}\left(\Phi_{\text {ref }}^{2}-z_{4}\right)$
In (24)-(25), the quantities $p\left(x_{6} x_{5}-x_{7} x_{4}\right) / J$ and $2 a_{1}\left(x_{6} x_{4}+x_{7} x_{5}\right)$ stand up as virtual control signals. If these were the actual control signals, the error system (24)-(25) could be globally asymptotically stabilized letting $p\left(x_{6} x_{5}-x_{7} x_{4}\right) / J=\mu_{1}$ and $2 a_{1}\left(x_{6} x_{4}+x_{7} x_{5}\right)=v_{1}$ with:

$\stackrel{\text { def }}{=} c_{3} z_{3}+\dot{\Omega}_{\text {ref }}+T_{L} / J+f\left(\Omega_{r e f}-z_{3}\right) / J$
$v_{1} \stackrel{\text { def }}{=} c_{4} z_{4}+2 \Phi_{\text {ref }} \dot{\Phi}_{\text {ref }}+2 L_{\text {seq }} \bar{\delta}\left(\Phi_{\text {ref }}^{2}-z_{4}\right)$

where $c_{3}$ and $c_{4}$ are any positive design parameters. As the quantities $p\left(x_{6} x_{5}-x_{7} x_{4}\right) / J$ and $2 a_{1}\left(x_{6} x_{4}+x_{7} x_{5}\right)$ are not the actual control signals, they cannot be let equal to $\mu_{1}$ and $v_{1}$, respectively. Nevertheless, the expressions of $\mu_{1}$ and $v_{1}$ are retained as first stabilizing functions. Introduce the errors:

$z_{5}=\mu_{1}-p\left(x_{6} x_{5}-x_{7} x_{4}\right) / J$

$z_{6}=v_{1}-2 a_{1}\left(x_{6} x_{4}+x_{7} x_{5}\right)$

Then, using the notations (26) to (31), the dynamics of $z_{3}$ and $\mathrm{z}_{4}$, can be rewritten as follows:

$\dot{z}_{3}=-c_{3} z_{3}+z_{5}$

$\dot{z}_{4}=-c_{4} z_{4}+z_{6}$

Similarly, the time-derivative of $V_{3}$ can be expressed, in function of the new errors, as follows:

$\dot{V}_{3}=-c_{3} z_{3}^{2}-c_{4} z_{4}^{2}+z_{3} z_{5}+z_{4} z_{6}$

Step 2. The second design step consists in choosing the actual control signals, $u_{2}$ and $u_{3}$, so that the system with states $\left(z_{3}, z_{4}, z_{5}, z_{6}\right)$ be asymptotically stable. It follows from $(30)$ :

$\dot{z}_{5}=\dot{\mu}_{1}-p\left(\dot{x}_{6} x_{5}+x_{6} \dot{x}_{5}-\dot{x}_{7} x_{4}-x_{7} \dot{x}_{4}\right) / J$

Using (6c-g) and (26), (35) gives:

$$
\begin{aligned}
& \dot{z}_{5}=\mu_{2}+p a_{3} x_{2}\left(x_{7} u_{2}-x_{6} u_{3}\right) / J \\
& \text { with } \\
& \begin{aligned}
\mu_{2} & =c_{3}\left(-c_{3} z_{3}+z_{5}\right)+\ddot{\Omega}_{r e f}+\dot{T}_{L} / J \\
& +p\left(f / J+L_{s e q} \bar{\delta}+a_{2}\right)\left(x_{6} x_{5}-x_{7} x_{4}\right) / J \\
& +p^{2} a_{3} x_{3}\left(x_{6}{ }^{2}+x_{7}{ }^{2}\right) / J-\left(f T_{L}\right) / J^{2}-f^{2} x_{3} / J^{2} \\
& +p^{2} x_{3}\left(x_{7} x_{5}+x_{6} x_{4}\right) / J
\end{aligned}
\end{aligned}
$$

Similarly, it follows from (31) that $z_{6}$ undergoes the following differential equation:

$\dot{z}_{6}=\dot{v}_{1}-2 a_{1}\left(\dot{x}_{6} x_{4}+x_{6} \dot{x}_{4}+\dot{x}_{7} x_{5}+x_{7} \dot{x}_{5}\right)$

Using (6c-g) and (27), it follows from (38):

$\dot{z}_{6}=v_{2}-2 a_{1} a_{3} x_{2}\left(x_{6} u_{2}+x_{7} u_{3}\right)$

with

$$
\begin{aligned}
v_{2} & =\left(c_{4}-2 L_{s e q} \bar{\delta}\right)\left(-c_{4} z_{4}+z_{6}\right)+2 \Phi_{r e f} \ddot{\Phi}_{r e f}-2\left(a_{1}\right)^{2} \bar{I}_{s}^{2} \\
& +2 \dot{\Phi}_{r e f}^{2}+4 L_{s e q} \bar{\delta} \Phi_{r e f} \dot{\Phi}_{r e f}+2\left(L_{s e q} \dot{\bar{\delta}}-a_{1} \bar{\delta}\right) \bar{\Phi}_{r}^{2}
\end{aligned}
$$


$+2 a_{1} a_{3} p\left(x_{7} x_{4}-x_{5} x_{6}\right)+2 a_{1}\left(L_{s e q} \bar{\delta}+a_{2}\right)\left(x_{4} x_{6}+x_{5} x_{7}\right)$

where the derivative of $\bar{\delta}$ is obtained from (6i):

$\dot{\bar{\delta}}=\frac{d \bar{\delta}}{d \bar{\Phi}_{r}} \frac{d \bar{\Phi}_{r}}{d t}=\frac{d \bar{\delta}}{d \bar{\Phi}_{r}}\left(\frac{x_{6}}{\bar{\Phi}_{r}} \dot{x}_{6}+\frac{x_{7}}{\bar{\Phi}_{r}} \dot{x}_{7}\right)$

The derivatives $\dot{\Phi}_{r e f}$ and $\ddot{\Phi}_{r e f}$ are obtained using (20) and

(21). To analyze the error system, composed of equations (32-33), (36) and (39), let us consider the following augmented Lyapunov function candidate:

$V_{4}=V_{3}+0.5\left(z_{5}^{2}+z_{6}^{2}\right)$

Using (34), (36) and (39), its time-derivative along the trajectory of the state vector $\left(z_{3}, z_{4}, z_{5}, z_{6}\right)$ is:

$\dot{V}_{4}=-c_{3} z_{3}^{2}-c_{4} z_{4}^{2}+z_{5}\left(z_{3}+\mu_{2}+p a_{3} x_{2}\left(x_{7} u_{2}-x_{6} u_{3}\right) / J\right)$

$+z_{6}\left(z_{4}+v_{2}-2 a_{1} x_{2} a_{3}\left(x_{7} u_{3}+x_{6} u_{2}\right)\right)$

Adding $\quad c_{5} z_{5}^{2}-c_{5} z_{5}^{2}+c_{6} z_{6}^{2}-c_{6} z_{6}^{2} \quad$ to the right side of (43) and rearranging terms, yield:

$\dot{V}_{4}=-c_{3} z_{3}^{2}-c_{4} z_{4}^{2}-c_{5} z_{5}^{2}-c_{6} z_{6}^{2}$

$+z_{5}\left(z_{3}+\mu_{2}+c_{5} z_{5}+p a_{3} x_{2}\left(x_{7} u_{2}-x_{6} u_{3}\right) / J\right)$

$+z_{6}\left(z_{4}+v_{2}+c_{6} z_{6}-2 a_{1} x_{2} a_{3}\left(x_{7} u_{3}+x_{6} u_{2}\right)\right)$

where $c_{5}$ and $c_{6}$ are new arbitrary positive real design parameters. Equation (44) suggests that the control signals $u_{2}, u_{3}$ must set to zero the two quantities between curly brackets (on the right side of (44)). Letting these quantities equal to zero and solving the resulting second-order linear equation system with respect to $\left(u_{2}, u_{3}\right)$, give the following control law:

$\left[\begin{array}{l}u_{2} \\ u_{3}\end{array}\right]=\left[\begin{array}{ll}\lambda_{0} & \lambda_{1} \\ \lambda_{2} & \lambda_{3}\end{array}\right]^{-1}\left[\begin{array}{l}-z_{3}-c_{5} z_{5}-\mu_{2} \\ -z_{4}-c_{6} z_{6}-v_{2}\end{array}\right]$

with:

$\lambda_{0}=p a_{3} x_{7} x_{2} / J, \lambda_{3}=-2 a_{1} x_{7} x_{2}, \lambda_{2}=-2 a_{1} x_{6} x_{2}$,

$\lambda_{1}=-p a_{3} x_{6} x_{2} / J$,

Note that the determinant $D$ of the matrix on the right side of (45) never vanishes in practice due to the machine remnant flux. $D=\lambda_{0} \lambda_{3}-\lambda_{1} \lambda_{2}=-2 p a_{1} a_{3} x_{2}^{2}\left(x_{6}^{2}+x_{7}^{2}\right) / J$.

Substituting the control law (45) to $\left(u_{2}, u_{3}\right)$ on the right side of (44) yields: $\dot{V}_{4}=-c_{3} z_{3}^{2}-c_{4} z_{4}^{2}-c_{5} z_{5}^{2}-c_{6} z_{6}^{2}$

As this is a negative definite function of the state vector $\left(z_{3}, z_{4}, z_{5}, z_{6}\right)$, the closed-loop system is globally asymptotically stable [4].

The result thus established is more precisely formulated in the Theorem 1, where the following notations are used:

$Z_{1}=\left[\begin{array}{lll}z_{1} & z_{2} & k\end{array}\right]^{T} ; Z_{2}=\left[\begin{array}{llll}z_{3} & z_{4} & z_{5} & z_{6}\end{array}\right]^{T} Z=\left[\begin{array}{ll}Z_{1} & Z_{2}\end{array}\right]^{T}$ (48a)

$b_{2}=\sqrt{2} E C^{-1} ; b_{3}=d E^{-2} ; \varepsilon=\omega_{e}^{-1}$

$A=\left(\begin{array}{cc}A_{1} & \mathrm{O}_{(3,4)} \\ \mathrm{O}_{(4,3)} & A_{2}\end{array}\right) \in I R^{7 \times 7}$

with
$A_{1}=\left(\begin{array}{ccc}-c_{1} & 0 & 0 \\ 0 & 0 & b_{0} \\ 0 & -b_{1} & -d\end{array}\right) A_{2}=\left(\begin{array}{cccc}-c_{3} & 0 & 1 & 0 \\ 0 & -c_{4} & 0 & 1 \\ -1 & 0 & -c_{5} & 0 \\ 0 & -1 & 0 & -c_{6}\end{array}\right)$

$f(Z, t)=\left[\begin{array}{llll}0 & \left(b_{0} k \cos \left(2 \omega_{e} t\right)+b_{2} z_{1} \cos \left(\omega_{e} t\right)\right) & 0 & 0_{4}^{T}\end{array}\right] \in I R^{7}(48 \mathrm{e})$

$g=\left[\begin{array}{llll}0 & -C^{-1} & b_{3} & 0 \\ 4\end{array}\right]^{T} \in I R^{7}$

$h=\left[\begin{array}{llll}0 & 1 & -d C E^{-2} & 0_{4}{ }^{T}\end{array}\right]^{T} \in I R^{7}$

where $0_{4}$ denotes the null vector of $I R^{4}$

$\rho\left(Z_{2}, t\right)=\frac{j}{p^{2} a_{3} \bar{\Phi}_{r}^{2}} J^{2}\left(z_{5}-\mu_{1}\right)-\frac{l}{\left(2 a_{1}\right)^{2} \bar{\Phi}_{r}^{2}}\left(v_{1}-z_{6}\right)$
$j=-\left(z_{3}+c_{5} z_{5}+c_{3}\left(-c_{3} z_{3}+z_{5}\right)+\ddot{\Omega}_{r e f}+\dot{T}_{L} / J-f T_{L} / J^{2}\right.$
$\quad+\left(f / J+L_{s e q} \bar{\delta}+a_{2}\right)\left(\mu_{1}-z_{5}\right)-f^{2}\left(\Omega_{r e f}-z_{3}\right) / J^{2}$
$\left.\quad+p^{2} a_{3}\left(\Omega_{r e f}-z_{3}\right)\left(\Phi_{r e f}{ }^{2}-z_{4}\right) / J\right)+p^{2}\left(\Omega_{r e f}-z_{3}\right)\left(v_{1}-z_{6}\right) / 2 a_{1} J$

$l=-\left(z_{4}+c_{6} z_{6}+\left(c_{4}-2 L_{s e q} \bar{\delta}\right)\left(-c_{4} z_{4}+z_{6}\right)+4 L_{s e q} \bar{\delta} \Phi_{\text {ref }} \dot{\Phi}_{\text {ref }}+2 \dot{\Phi}_{r e f}^{2}\right.$

$+\left(L_{s e q} \bar{\delta}+a_{2}\right)\left(v_{1}-z_{6}\right)+2\left(L_{s e q} \dot{\bar{\delta}}-a_{1} \bar{\delta}\right)\left(\Phi_{r e f}^{2}-z_{4}\right)+2 \Phi_{\text {ref }} \ddot{\Phi}_{\text {ref }}$

$-2\left(a_{1}\right)^{2}\left(J^{2}\left(z_{5}-\mu_{1}\right)^{2} / p^{2}+\left(v_{1}-z_{6}\right)^{2} /\left(2 a_{1}\right)^{2}\right) / \bar{\Phi}_{r}^{2}+2 a_{1} a_{3} J\left(z_{5}-\mu_{1}\right)$

Theorem 1 (main result). Consider the system including the $A C / D C / A C$ power converters and the induction motor connected in tandem, as shown in Fig.1. For control design purpose, the system has been represented by its average model $(6 a-j)$. Consider the controller defined by the control laws (10), (18) and (45) where all design parameters, namely $c_{1}, c_{2}, c_{3}, c_{4}, c_{5}, c_{6}$ and $d$ are positive. Then, one has the following results:

1) The resulting closed-loop system satisfies the state-space equation:

$\dot{Z}=A Z+f(Z, t)+g \rho\left(Z_{2}, t\right)+h \dot{y}_{\text {ref }}$

2) Let $v_{\text {dcref }}$ and $\Omega_{\text {ref }}$ be either constant or periodic signals, with period $N \pi / \omega_{e}$ (for some positive integer $N$ ), and suppose that they are time derivable (up to second order for $\Omega_{\text {ref }}$ ) with bounded derivatives. Then, there exists a positive real $\varepsilon^{*}$ such that, if $0<\varepsilon<\varepsilon^{*}$ then:

a) The tracking error $z_{2}=y-y_{\text {ref }}$ and the tuning parameter $k$ are harmonic signals whose amplitudes are continuously depending on $\varepsilon$.

b) Furthermore, one has:

(i) $\lim _{\varepsilon \rightarrow 0} z_{2}(t, \varepsilon)=0$; (ii) $\lim _{\varepsilon \rightarrow 0} k(t, \varepsilon)=\bar{\rho}\left(0_{4}\right) / b_{0} C$ (50)

where $\bar{\rho}\left(0_{4}\right)$ denotes the mean value of the periodic time function $\rho\left(0_{4}, t\right)$

\section{SIMULATION}

The simulated experimental set-up has the following characteristics: Supply network: $220 \mathrm{~V} / 50 \mathrm{~Hz}, \mathrm{AC} / \mathrm{DC} / \mathrm{AC}$ converters: $\mathrm{L}_{1}=15 \mathrm{mH} ; \mathrm{C}=1.5 \mathrm{mF}$; Induction motor 
characteristics: nominal power . Controller design parameters: $\mathrm{c}_{1}=1000, \mathrm{c}_{2}=30, \mathrm{c}_{3}=100, \mathrm{c}_{4}=400$, $\mathrm{c}_{5}=500, \mathrm{c}_{6}=1000, \mathrm{~d}=100$.

The load torque $T_{L}$ is a step-like function set first to 0 $\mathrm{Nm}$, then, it steps to $10 \mathrm{Nm}$ at $\mathrm{t}=6 \mathrm{~s}$, to $20 \mathrm{Nm}$ at $\mathrm{t}=8 \mathrm{~s}$, to $30 \mathrm{Nm}$ at $\mathrm{t}=10 \mathrm{~s}$, to $40 \mathrm{Nm}$ at $\mathrm{t}=12 \mathrm{~s}$, to $50 \mathrm{Nm}$ at $\mathrm{t}=14 \mathrm{~s}$ and to $-20 \mathrm{Nm}$ at $\mathrm{t}=16 \mathrm{~s}$.

The controller performances are illustrated by Figs 5 to 8 . Fig. 5 shows that the DC-link voltage $x_{2}=\bar{v}_{d c}$ is well regulated and quickly settles down after each change in the speed reference or load torque. The resulting input current $i_{e}$ is illustrated by Fig 8. It is seen that the current amplitude changes whenever the speed reference or the load torque vary. But the current frequency is sensitive to these changes. Specifically, the current remains (almost) all time in phase with the supply net voltage complying with the PFC requirement. Figs 6 and 7 show that the motor speed and the rotor flux norm do perfectly converge to their respective references. The tracking quality is quite satisfactory for both controlled variables ( $\left.\Omega, \Phi_{r}\right)$.

\section{CONCLUSION}

This paper has addressed the problem of controlling associations including an $\mathrm{AC} / \mathrm{DC}$ rectifier, a DC/AC inverter and an induction motor. Unlike most previous works, the motor magnetic characteristic is let to be what it is i.e. a saturating curve. The system dynamics have been described by the averaged $7^{\text {th }}$ order nonlinear state-space model (6a-j). It was formally established that the proposed controller achieves the objectives for which it was designed: (i) almost unitary power factor; (ii) tight DC-link voltage regulation; (iii) satisfactory rotor speed reference tracking and rotor flux norm regulation, over a wide range of load torque variation. In all operation conditions, the proposed SDOF controller leads to a smaller absorbed stator current, compared to that produced by a constant flux controller (see Fig 9). These results are confirmed by many simulations.

\section{REFERENCES}

[1] Elfadili A., Giri F., Ouadi H., Dugard L., and El Magri A. "Induction Machine Control in Presence of Magnetic Saturation. Speed Regulation with Optimized Flux Reference". European Control Conference, August 23-26, 2009, Budapest, Hungary.

[2] Sira.H and R. Silva. 'Control design techniques in power electronics devices'. Springer. (2006).

[3] Heinemann G. and W. Leonhard 'Self-tuning field orientated control of an induction motor drive', Proceedings of international power electroniques conference April 2-6, 1990 Shinjuku Tokyo, Japan.

[4] Khalil H. 'Nonlinear systems'. Prentice Hall. (2003).

[5] Krstic M., I. Kanellakopoulos, and P. Kokotovic. 'Nonlinear and adaptive control design'. John Wilay \& Sons, Inc, 1995.

[6] Nuno M. Silva1, P. António Martins, S. Adriano. Carvalho, 'Torque and speed modes simulation of a DTC controlled induction motor' Proceedings of the 10th Mediterranean Conference on Control and Automation - MED2002 Lisbon, Portugal, July 9-12, (2002)Y. Yorozu,

[7] Ouadi. H, F. Giri, and L. Dugard. "Modeling saturated induction motors". IEEE Conference on Control Applications (CCA'04), Taipei, Taiwan. 2004 Vol.1, pp. $75-80$.
[8] Singh B., G. Bhuvaneswari, and V. Garg. 'Improved Power Quality AC-DC Converter for Electric Multiple Units in Electric Traction'. Power India Conference, pp. 6, 2006.

[9] Elfadili A., Giri F. El Magri A, Ouadi H., Dugard L., and A. Aboulouafa. "“Induction Motor Control through AC/DC/AC Converters Formal analysis of speed regulation performances and power factor correction" IFAC American Control Conference -ACC2010 Baltimore, Maryland, USA
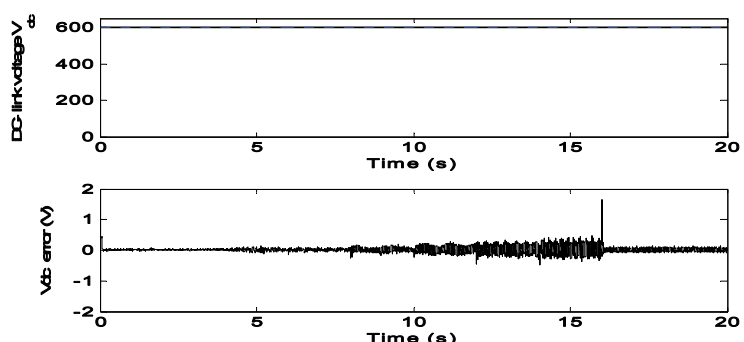

Fig.5. DC-link voltage $v_{d c}$ response Upper: reference and measured DClink voltage; lower: error control

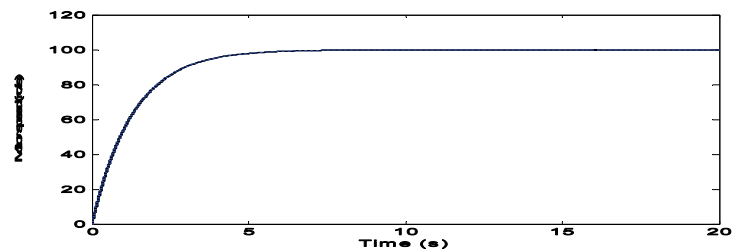

Fig.6. Dotted: Speed reference. Solid: Identical speed responses obtained by the state-dependent optimized flux (SDOF) controller and the constant flux controller.

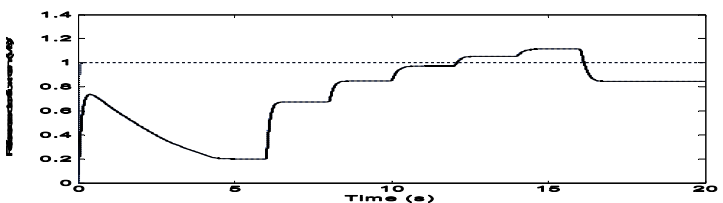

Fig.7. Rotor flux norm reference (Wb) (solid: state-dependent optimized flux, dotted: constant flux)

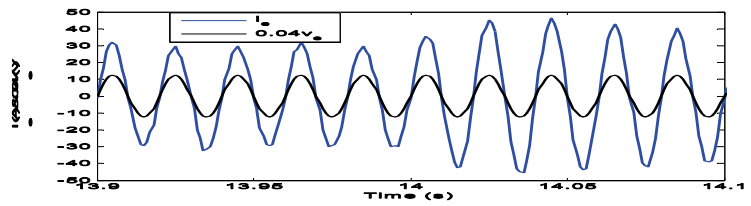

Fig.8. Unitary power factor checking in presence of a varying speed reference and load torque

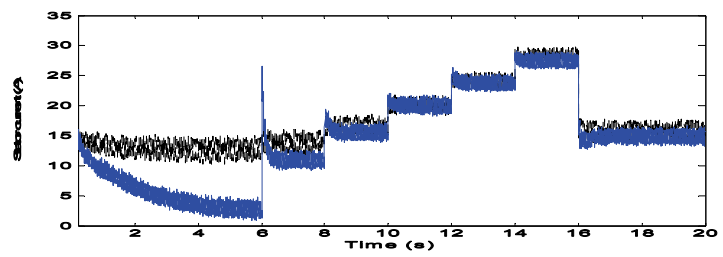

Fig 9: Absorbed stator current (A) (solid: SDOF controller, dotted: constant flux controller). 